\title{
Fotografia entre confronto e arte
}

\author{
Luiz Baltar*
}

Em recente entrevista para o blog Entretempos, um fotógrafo francês da agência Magnun Antoine D'Agata disse:

A melhor maneira de conhecer o mundo é confrontando-o, confrontando os outros. Tomando alguma atitude de risco. Esquecemos que a fotografia é explorar o mundo e mudar o entendimento sobre ele. Não sabemos muito, não sabemos nada no final, e com o pouco que sabemos temos de inventar um destino mais digno possível.

Vivemos em uma época na qual somos desencorajados a pensar a cidade como uma realização coletiva ou como um território em disputa constante. O Estado, as grandes corporações e o capital dominam a cidade e a transformam em um lugar de produção de lucro em vez de um lugar para se viver. Somos levados a acreditar que não existe outra possibilidade. Então nos vemos impotentes, insatisfeitos e sem saída. Fotografando comecei a explorar e mudar a percepção que tinha sobre o mundo. Acredito na fotografia como forma de expressão ativista e crítica, e com ela quero estabelecer um diálogo com as questões sociais, sobretudo no que diz respeito ao olhar sobre a cidade. Dedico uma grande parte da minha produção a documentar as várias maneiras de lutar pelo direito à cidade e busco refletir sobre algumas questões contemporâneas com as minhas imagens.

Comecei em 2009, fotografando o processo de remoções forçadas e as ocupações militares em diversas comunidades e favelas do Rio de Janeiro. Descobri que, com a fotografia, podia ser um militante social ativo sem fazer parte de partidos ou organizações políticas, simplesmente registrando e disponibilizando imagens para proporcionar maior visibilidade e empatia às causas ou, nas ocupações militares, inibindo violações de direitos com a presença de uma câmera registrando a ação.

\footnotetext{
* Fotógrafo documentarista formado pela Escola de Belas Artes (UFRJ) e pela Escola de Fotógrafos Populares. E-mail: <lbaltar@me.com>
} 
No entanto, não basta fotografar um assunto para que ele seja compreendido. Temos que lidar com a percepção condicionada pela grande mídia, com os estereótipos que marcam os moradores de territórios populares. Aí vem o maior desafio: mostrar, expor, desconstruir e dar visibilidade. Com o tempo percebi que, tanto do ponto de vista estético quanto do ponto de vista documental, era preciso buscar uma perspectiva diferente para retratar e, principalmente, criar empatia entre o espectador e os meus temas. Por isso, aos poucos fui rompendo com a estética narrativa do fotojornalismo e com sua pretensão de retratar a verdade. A realidade é subjetiva e é melhor compreendida pelas emoções.

Na edição de imagens que fiz para essa edição da Em Pauta, misturo fotos das minhas documentações sobre remoções, ocupações militares, manifestações e um trabalho mais autoral sobre mobilidade e as transformações urbanas do Rio de Janeiro. São fotografias expandidas no formato de panorâmicas ou longos instantâneos, que faço durante o percurso casa $\mathrm{x}$ trabalho, aproveitando os congestionamentos. Com esse trabalho quero falar do caos urbano que me impressiona e também dos momentos de contemplação e reflexão proporcionados pelo transporte coletivo. 


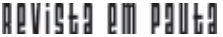

\} FOTOGRAFIA ENTRE CONFRONTO E ARTE - BALTAR, L. \}

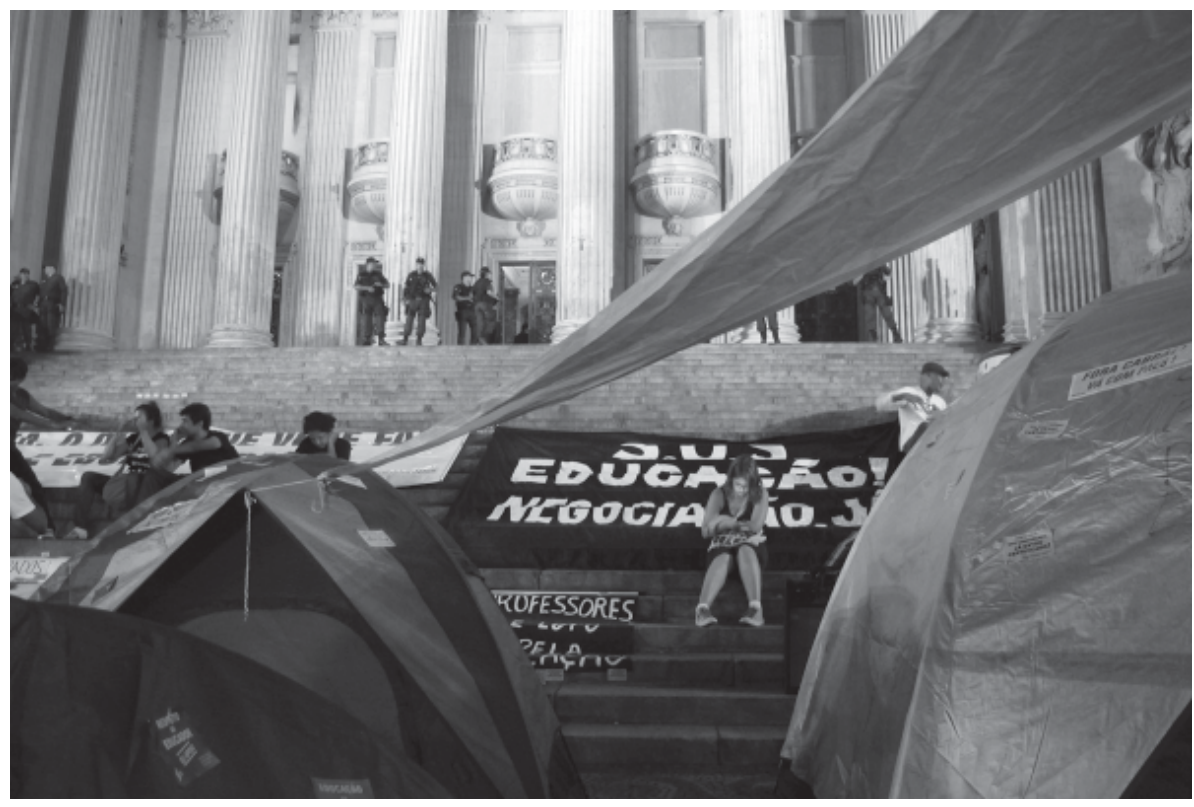

Ocupação da ALERJ. Professores da rede estadual acampados nas escadarias da Assembleia Legislativa do Rio de Janeiro (Alerj). ALERJ 12/09/2013. 


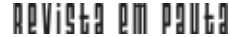

\} FOTOGRAFIA ENTRE CONFRONTO E ARTE - BALTAR, L. \}

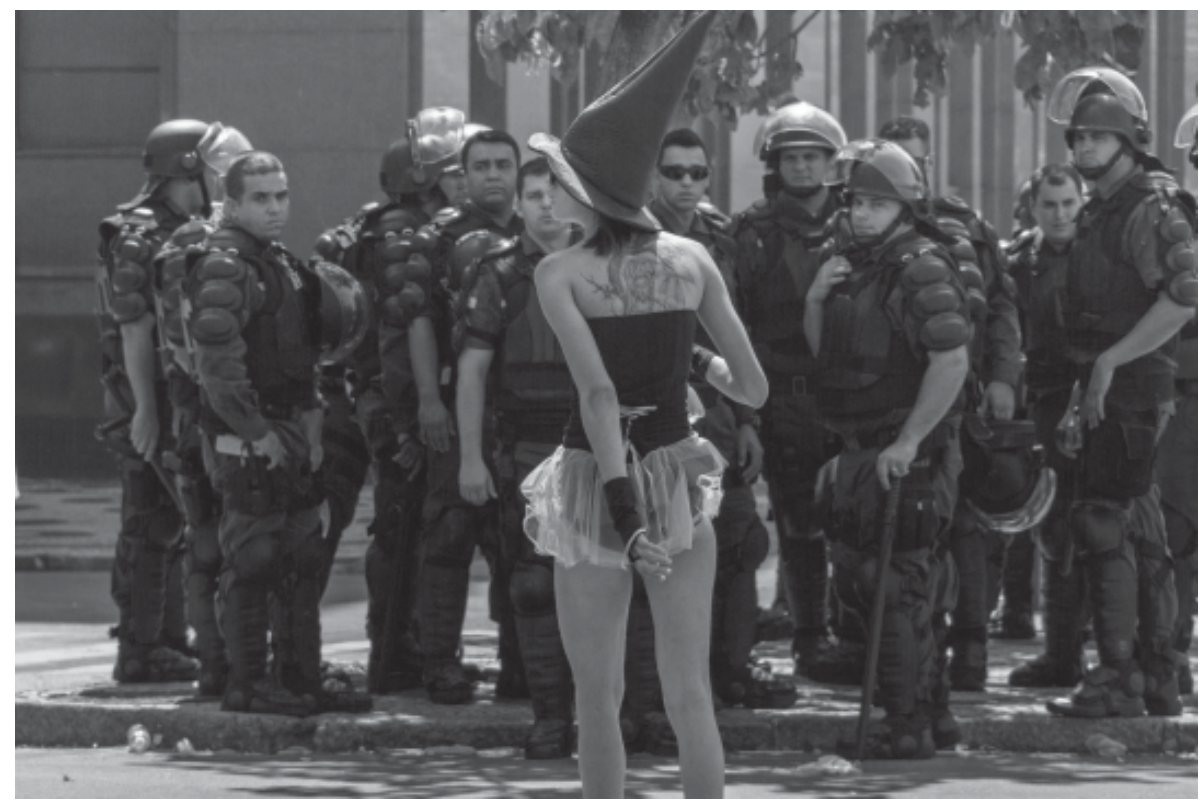

Carnaval e luta. Por não aceitar os acordos feitos entre a prefeitura e o sindicato, os garis do Rio paralisaram os serviços de limpeza da cidade durante o carnaval. A categoria mobilizada fez atos diários para pressionar o governo. O aparato de repressão como sempre presente. Central do Brasil 03/03/2014. 


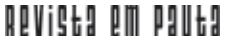

\} FOTOGRAFIA ENTRE CONFRONTO E ARTE - BALTAR, L. \}

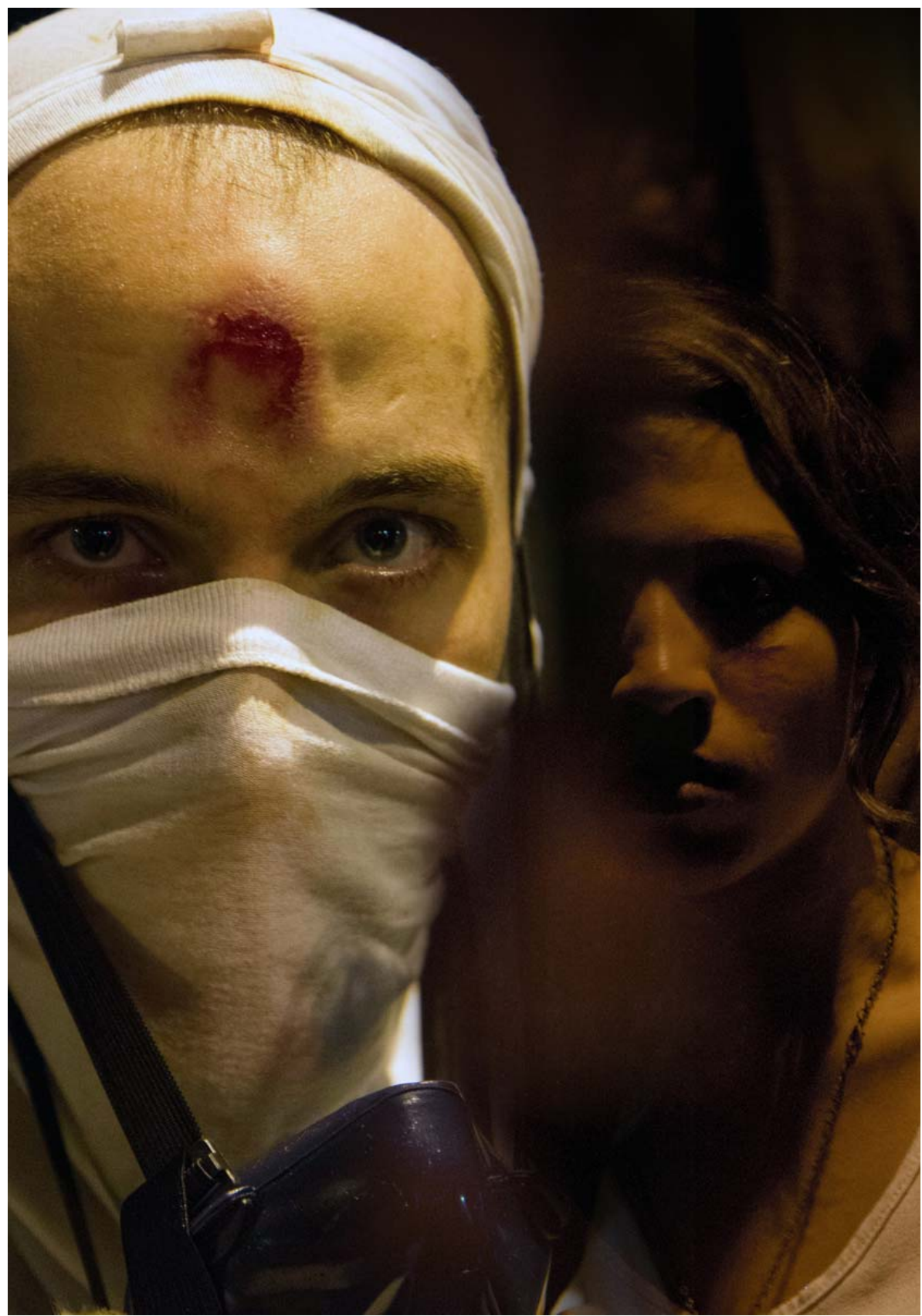

Jornadas de junho. Sem legenda. Rio de Janeiro 31/07/2015.

EM PAUTA, Rio de Janeiro - $1^{\circ}$ Semestre de 2015 - n. 35, v. 13, p. 203- 224 


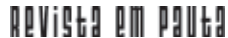

\} FOTOGRAFIA ENTRE CONFRONTO E ARTE - BALTAR, L. \}

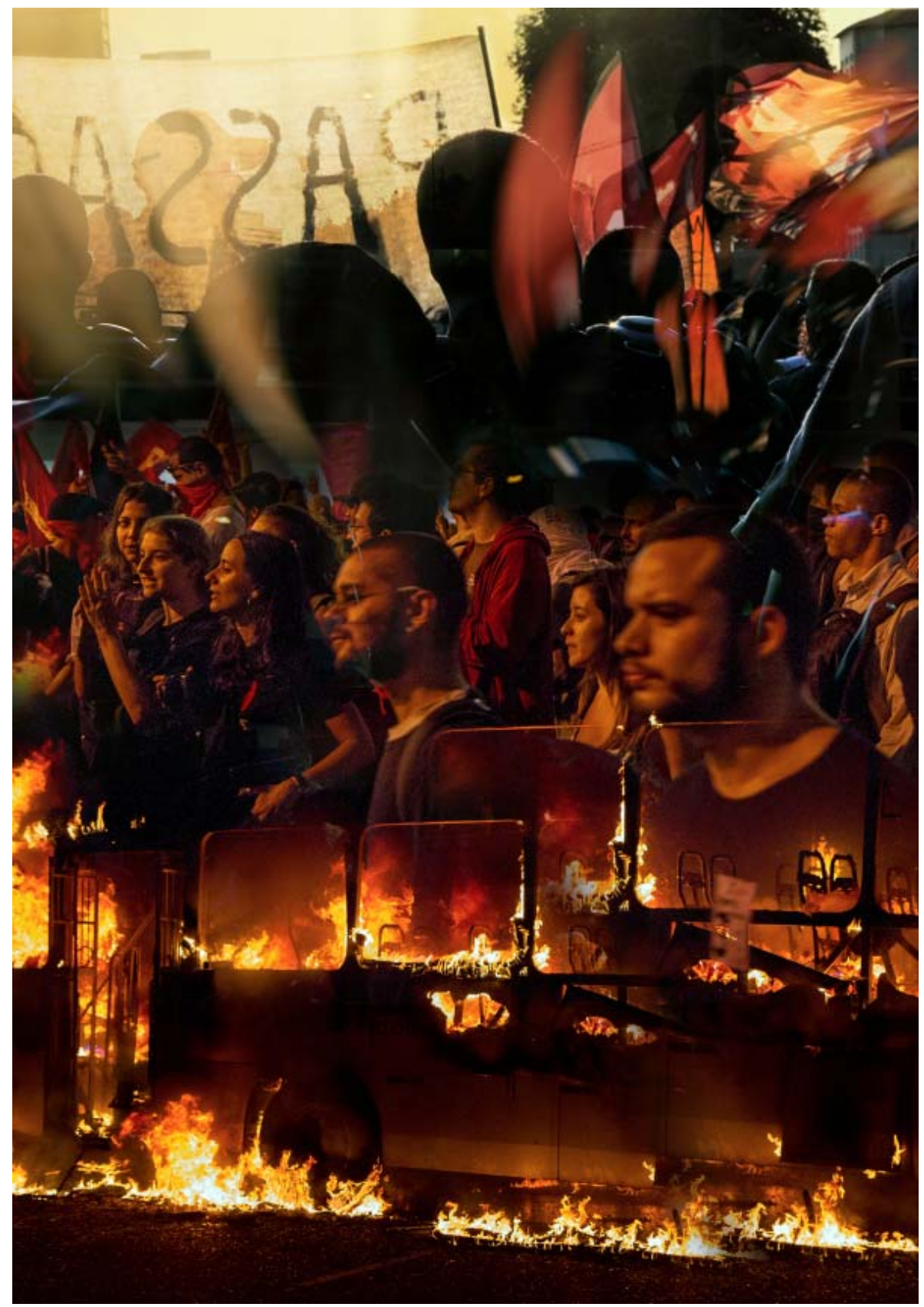

Jornadas de junho. Sem legenda. Rio de Janeiro 31/07/2015.

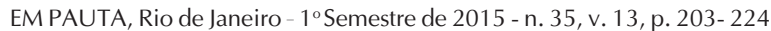




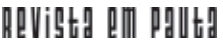

\} FOTOGRAFIA ENTRE CONFRONTO E ARTE - BALTAR, L. \}

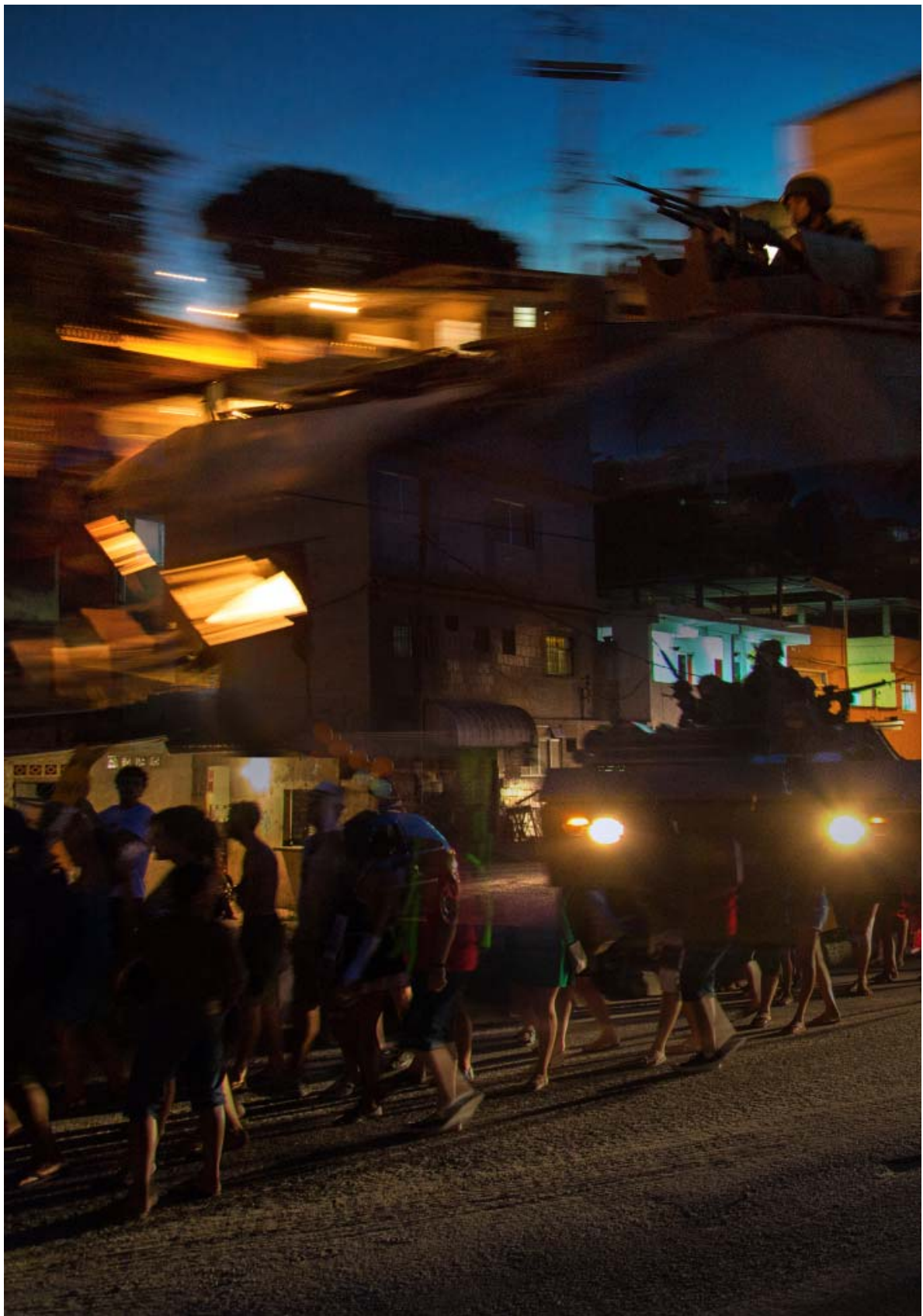

Ocupação militar na Maré. Sem legenda. Rio de Janeiro 31/07/2015

EM PAUTA, Rio de Janeiro - $1^{\circ}$ Semestre de 2015 - n. 35, v. 13, p. 203- 224 


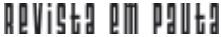

\} FOTOGRAFIA ENTRE CONFRONTO E ARTE - BALTAR, L. \}

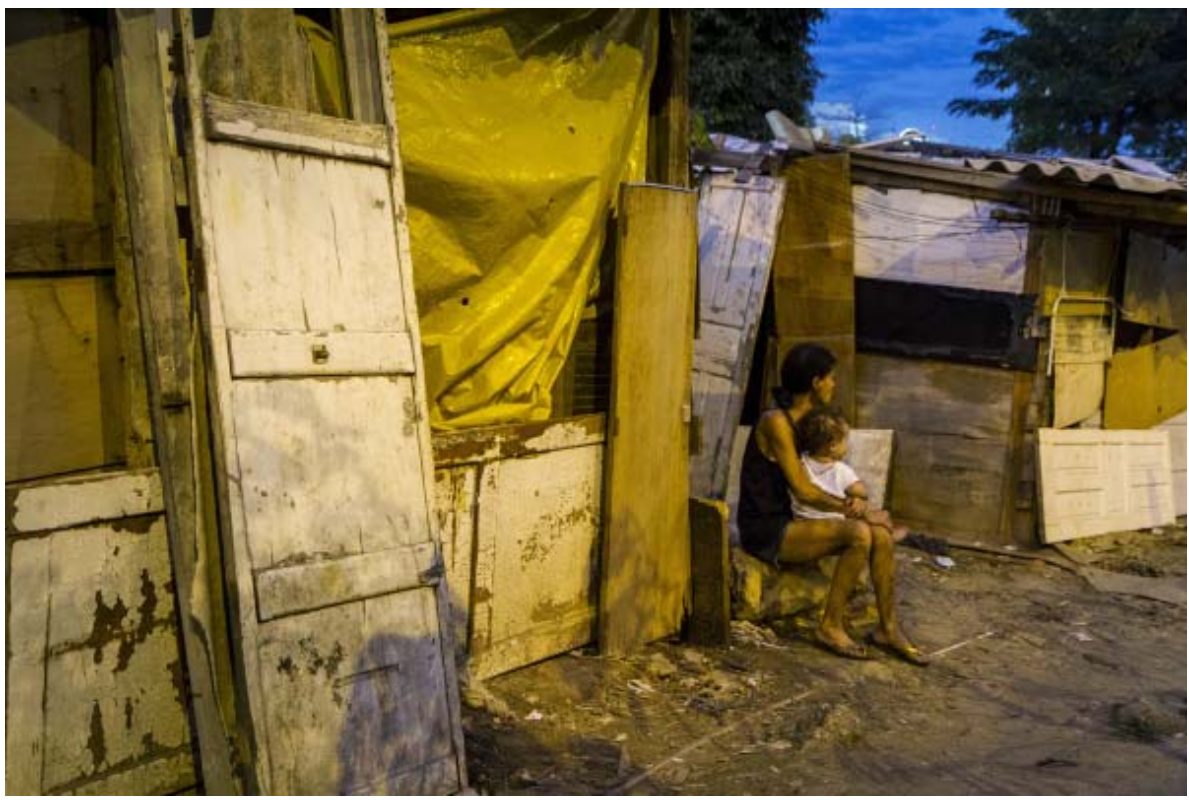

Ocupação Militar na Rocinha. 13 de novembro, uma operação juntando as polícias federal, militar, civil e forças armadas ocuparam o conjunto de favelas da Rocinha e Vidigal no Rio de Janeiro, prometendo "Choque de Paz", mas será essa a paz desejada? Rocinha 13/11/2011 


\section{ReVigta dil paltg}

\} FOTOGRAFIA ENTRE CONFRONTO E ARTE - BALTAR, L. \}

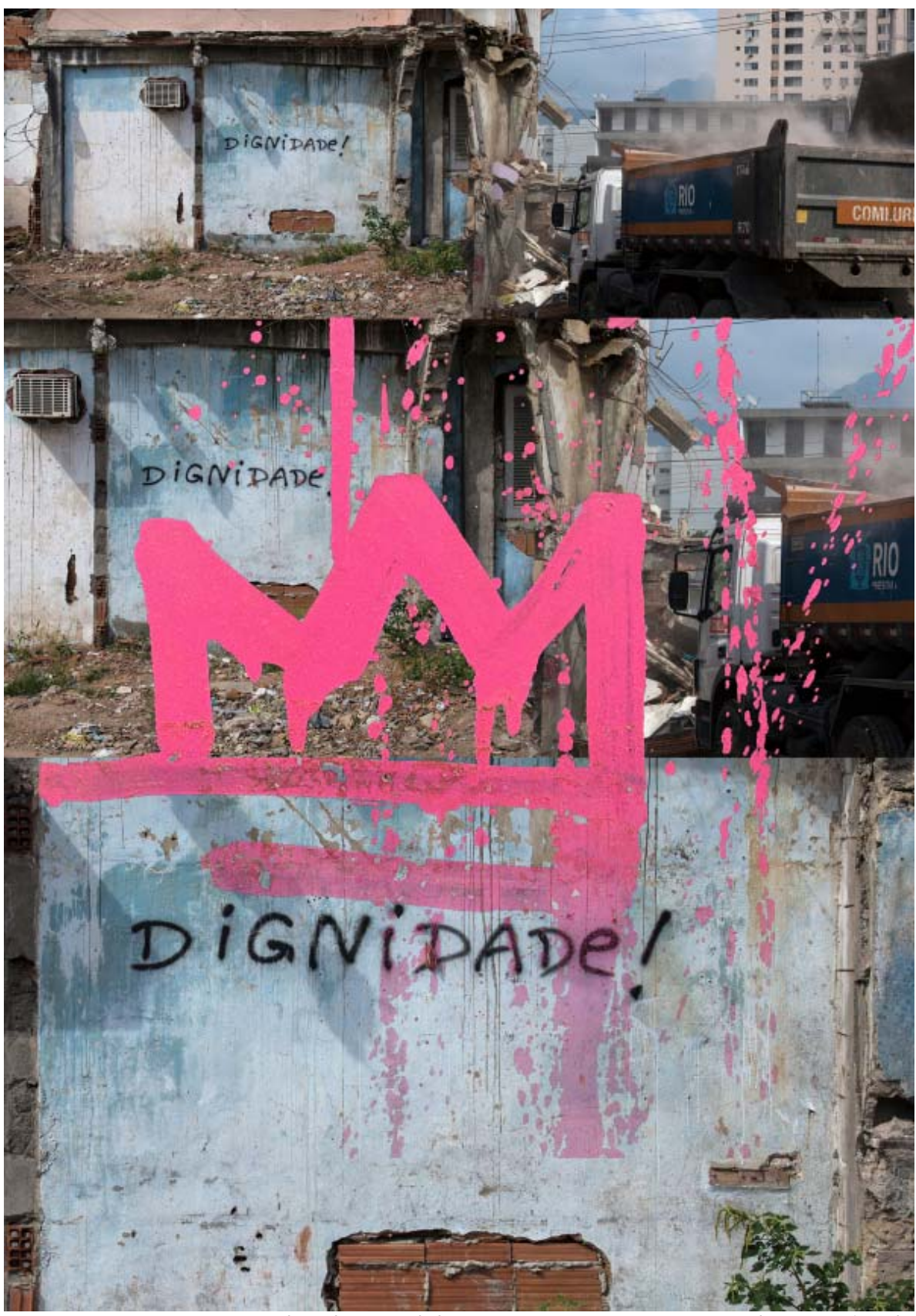

Os Moradores da comunidade Metrô Mangueira, resistem a tentativa de remoção forçada. Metrô Mangueira 30/05/2015

EM PAUTA, Rio de Janeiro - $1^{\circ}$ Semestre de 2015 - n. 35, v. 13, p. 203- 224 


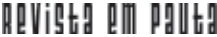

\} FOTOGRAFIA ENTRE CONFRONTO E ARTE - BALTAR, L. \}

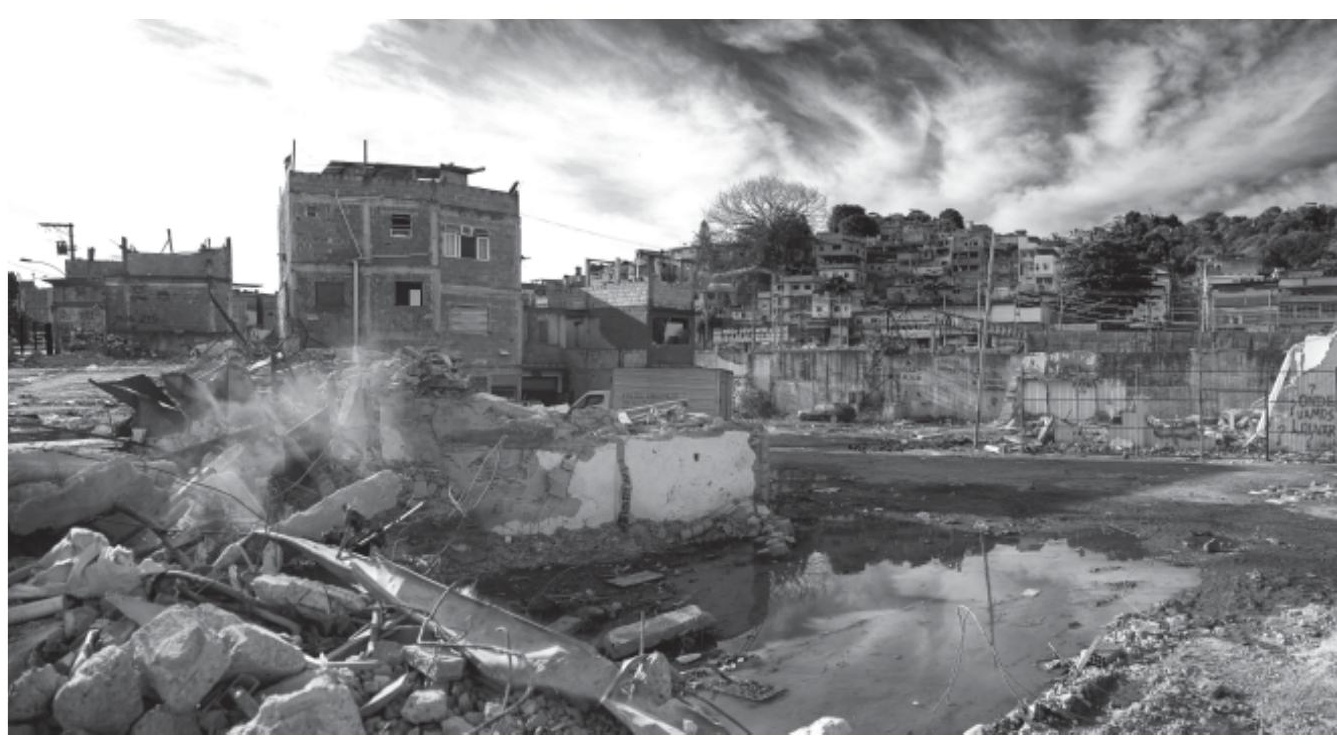

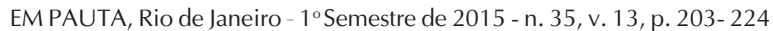




\section{ReVigta dil paltg}

\} FOTOGRAFIA ENTRE CONFRONTO E ARTE - BALTAR, L. \}

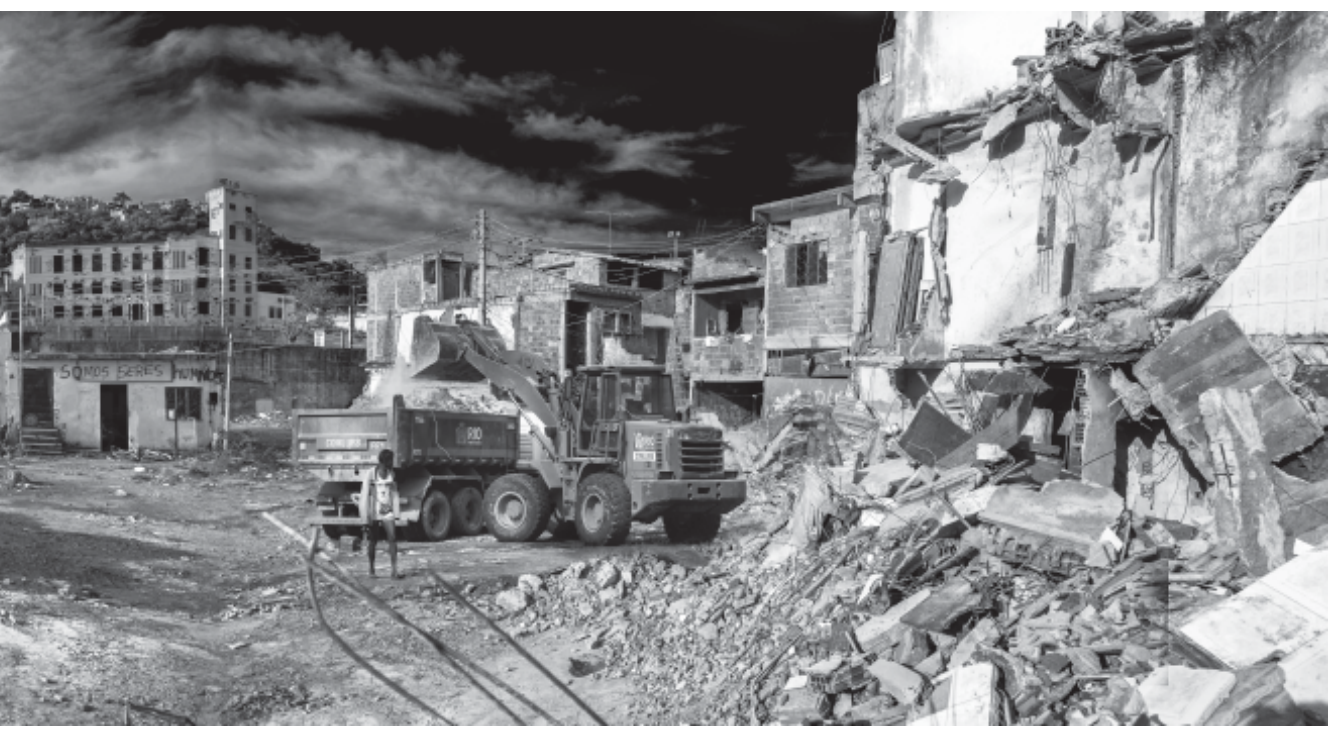

Os moradores da comunidade Metrô Mangueira, resistem a tentativa de remoção forçada. Metrô Mangueira 30/05/2015

EM PAUTA, Rio de Janeiro - $1^{\circ}$ Semestre de 2015 - n. 35, v. 13, p. 203- 224 


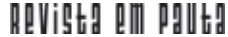

\} FOTOGRAFIA ENTRE CONFRONTO E ARTE - BALTAR, L. |

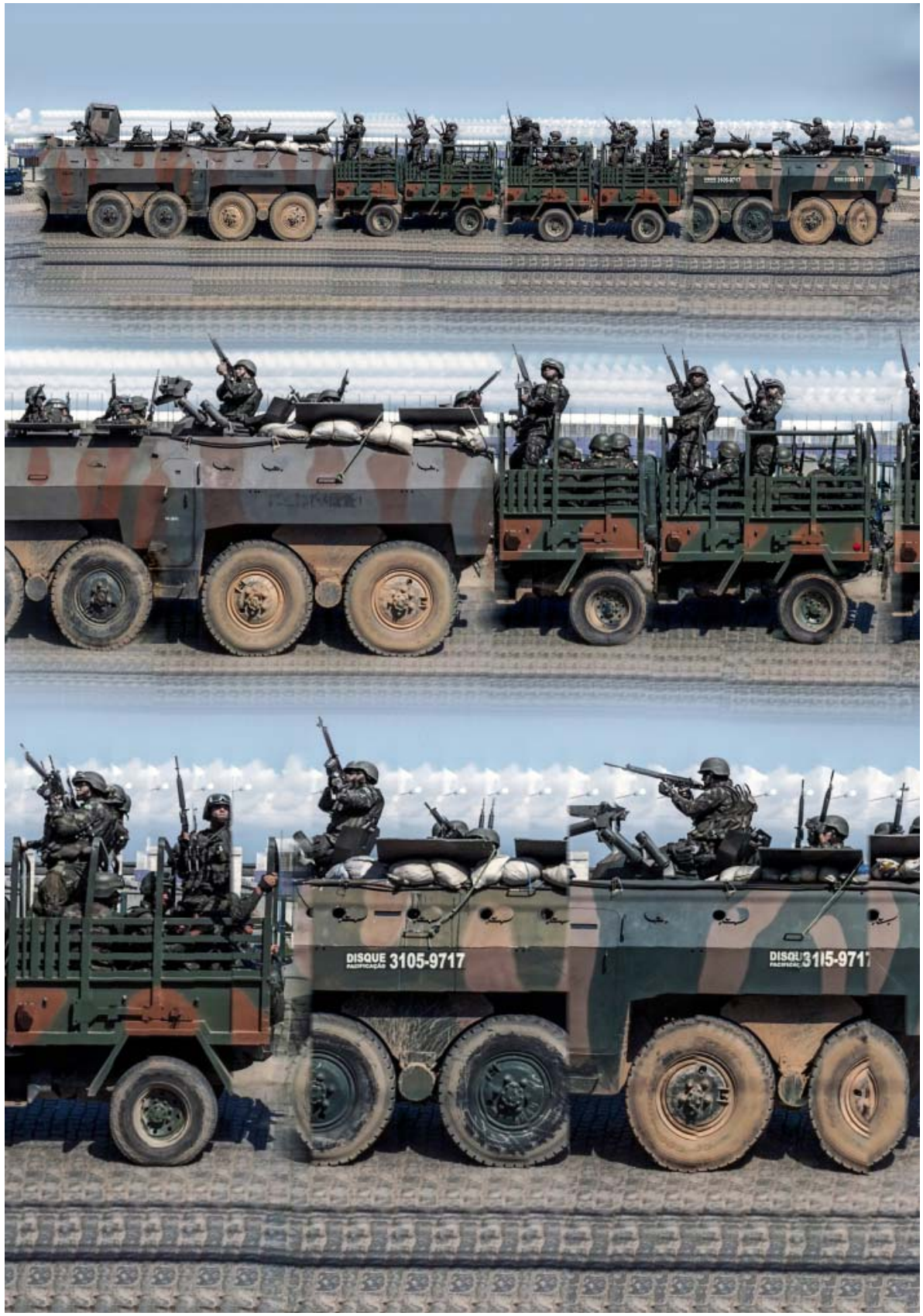

Sem Título. Ensaio autoral sobre ocupação militar na Maré.

Maré 31/07/2015

EM PAUTA, Rio de Janeiro - $1^{\circ}$ Semestre de 2015 - n. 35, v. 13, p. 203- 224 


\section{ReVigta dil paltg}

\} FOTOGRAFIA ENTRE CONFRONTO E ARTE - BALTAR, L. \}

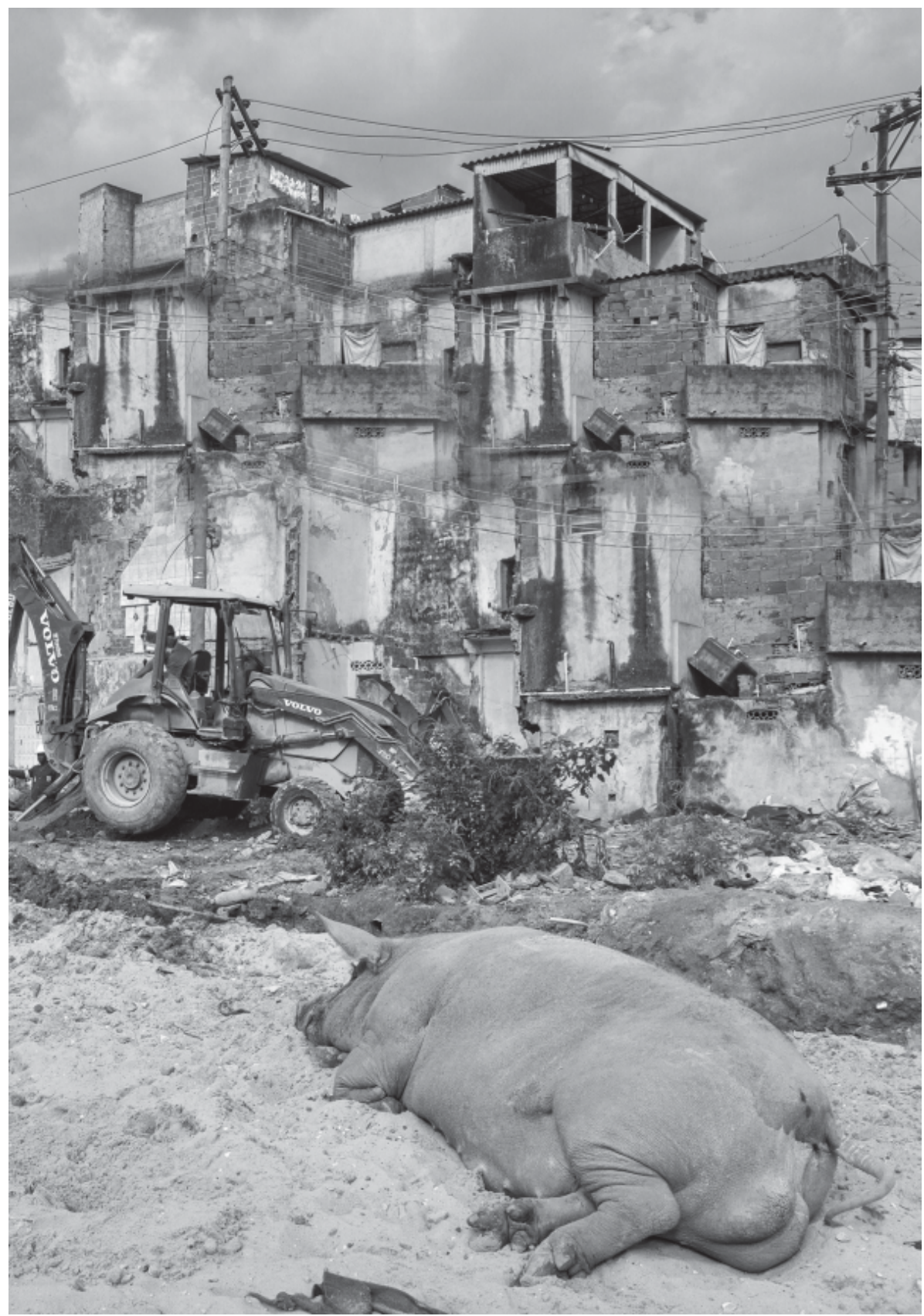

Remoções. Escombros, demoliç̃es e canteiros de obras que abrem enormes buracos que logo são preenchidos por esgoto que jorra em abundẩncia das tubulações rompidas por escavadeiras e tratores. Manguinhos 14/10/2012.

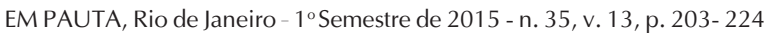




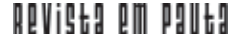

\} FOTOGRAFIA ENTRE CONFRONTO E ARTE - BALTAR, L. \}

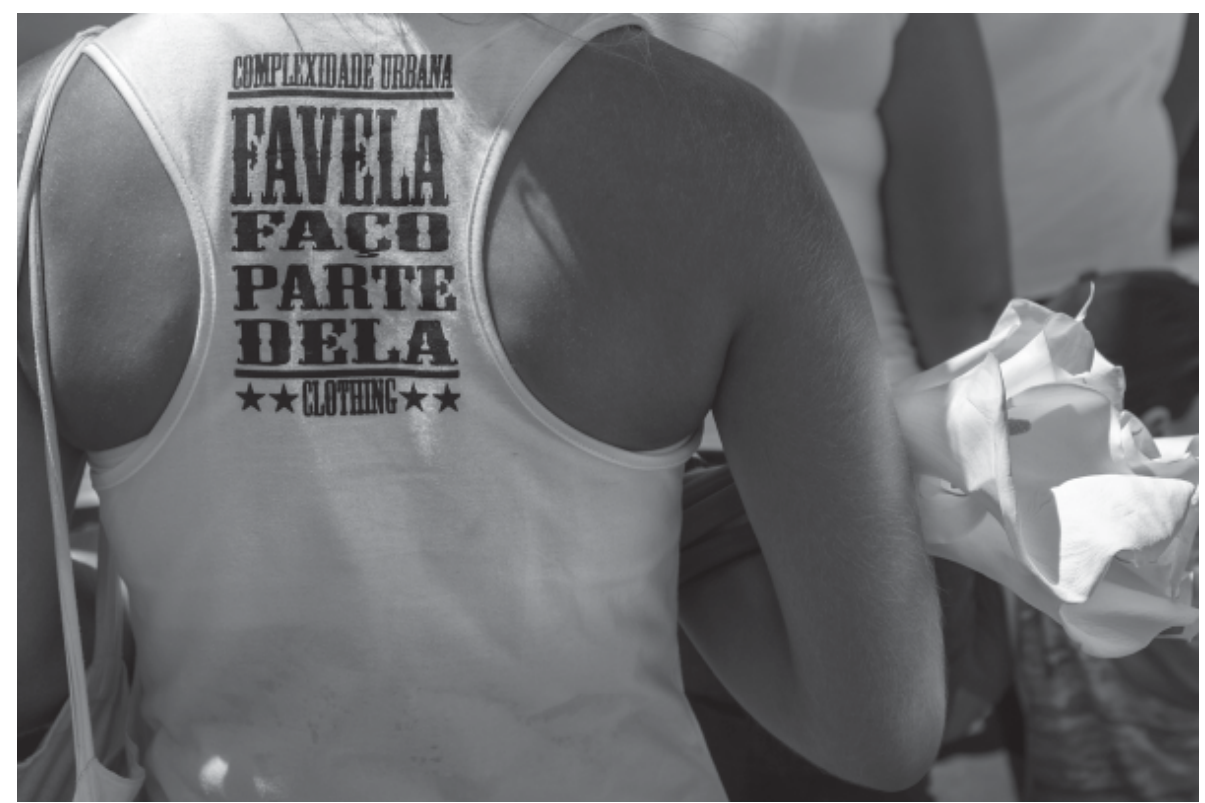

Marcha pela paz. Moradores, ativistas, coletivos e organizações de direitos humanos participam de caminhada pedindo paz. Alemão 11/10/2014 


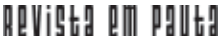

\} FOTOGRAFIA ENTRE CONFRONTO E ARTE - BALTAR, L. \}

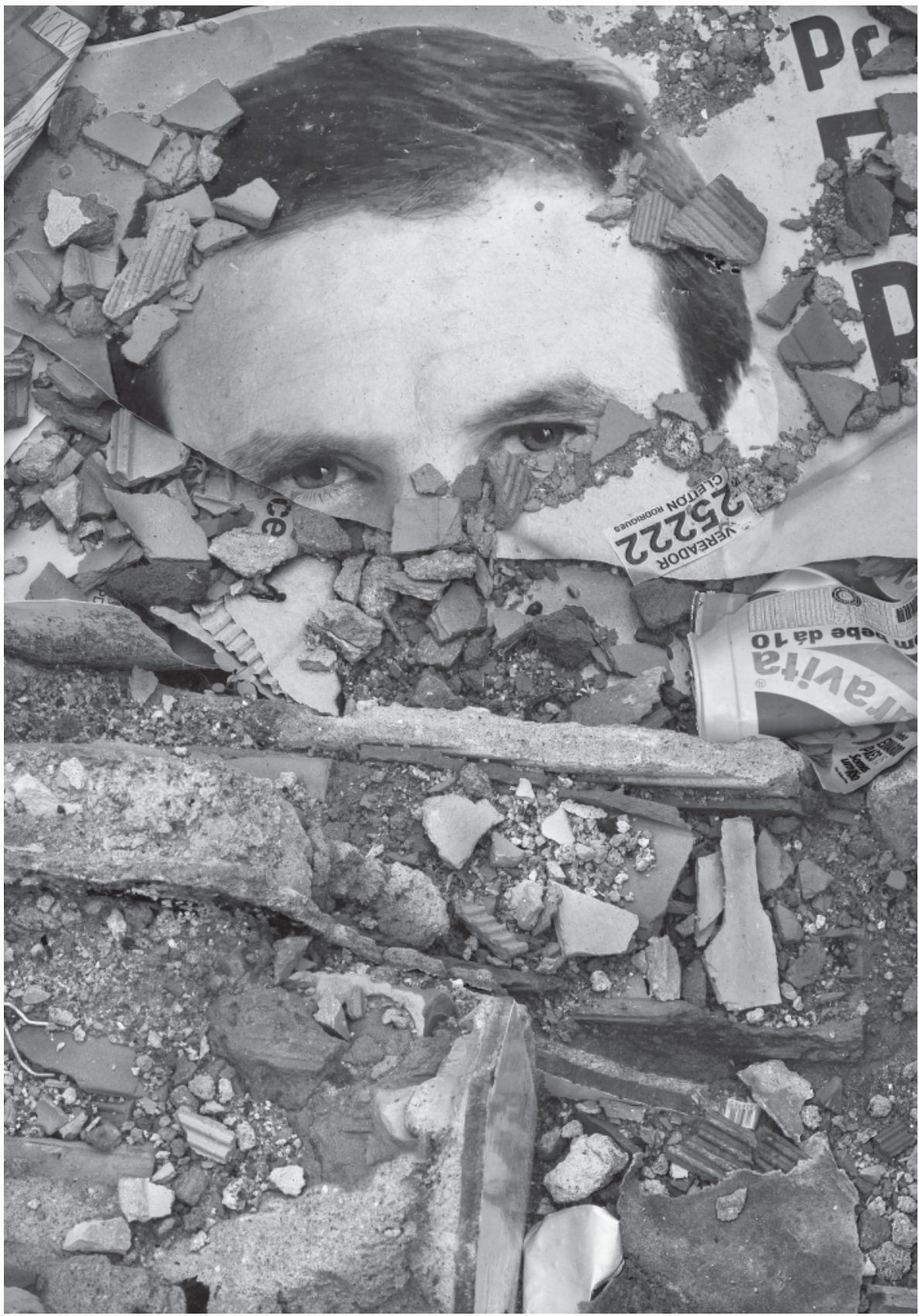

Lixo Eleitoral. Ensaio sobre as eleições de 2014. Rio de Janeiro 06/09/2014

EM PAUTA, Rio de Janeiro - $1^{\circ}$ Semestre de 2015 - n. 35, v. 13, p. 203- 224 


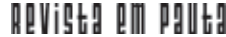

\} FOTOGRAFIA ENTRE CONFRONTO E ARTE - BALTAR, L. \}

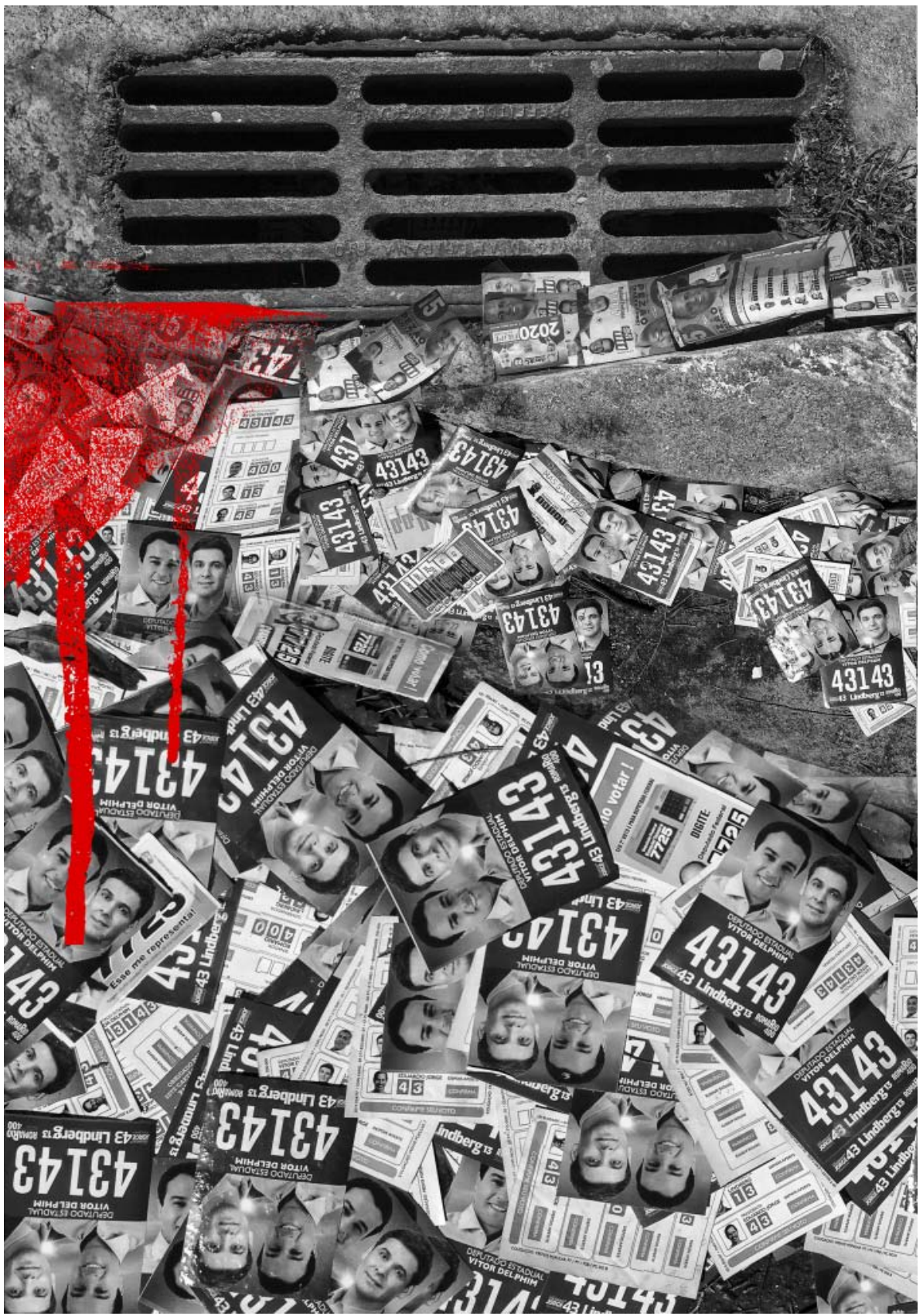

Lixo Eleitoral. Ensaio sobre as eleições de 2014.

Rio de Janeiro 06/09/2014

EM PAUTA, Rio de Janeiro - $1^{\circ}$ Semestre de 2015 - n. 35, v. 13, p. 203- 224 


\section{ReVigta dil paltg}

\} FOTOGRAFIA ENTRE CONFRONTO E ARTE - BALTAR, L. |

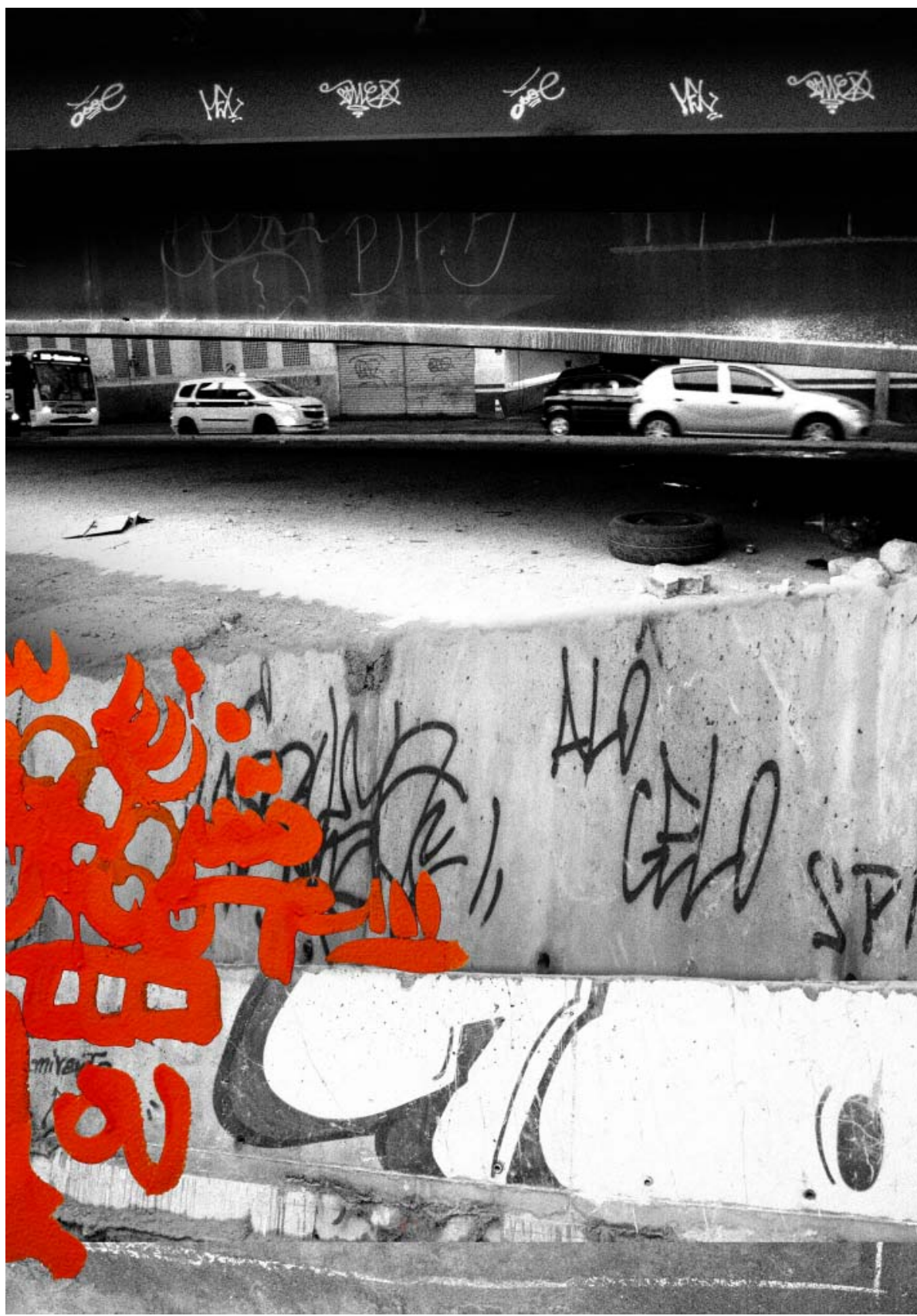

Adeus Perimetral. Documentação autoral sobre a derrubada do elevado da Perimetral Rio de janeiro10/08/2015

EM PAUTA, Rio de Janeiro - $1^{\circ}$ Semestre de 2015 - n. 35, v. 13, p. 203- 224

Revista da Faculdade de Serviço Social da Universidade do Estado do Rio de Janeiro 


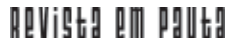

\} FOTOGRAFIA ENTRE CONFRONTO E ARTE - BALTAR, L. |

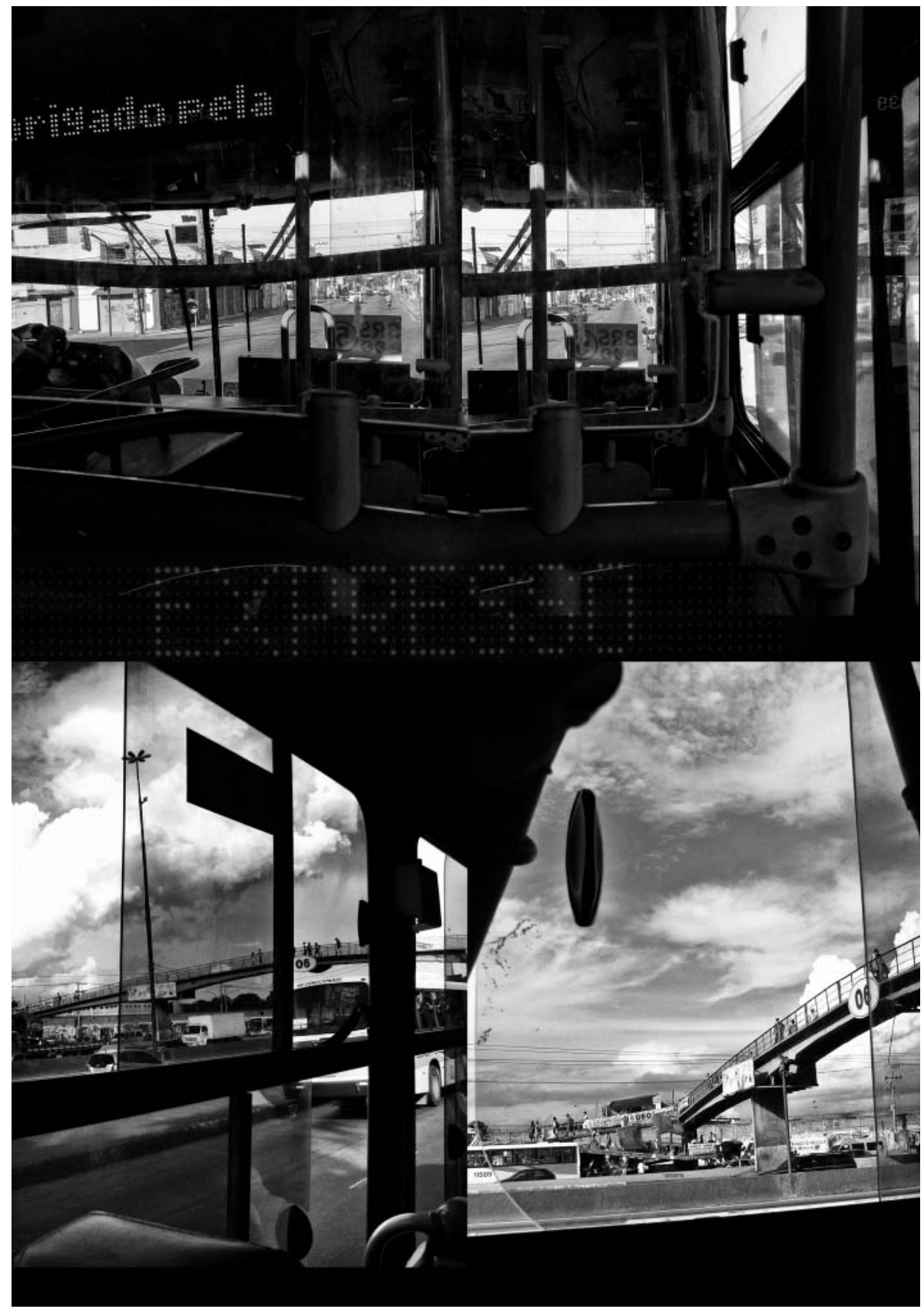

Ensaio Espelhos e Janelas. Documentação autoral sobre os deslocamentos através da cidade usando transporte coletivo. Rio de janeiro 31/07/2015

EM PAUTA, Rio de Janeiro - $1^{\circ}$ Semestre de 2015 - n. 35, v. 13, p. 203- 224 


\section{Revigta dil pallt}

\} FOTOGRAFIA ENTRE CONFRONTO E ARTE - BALTAR, L. |
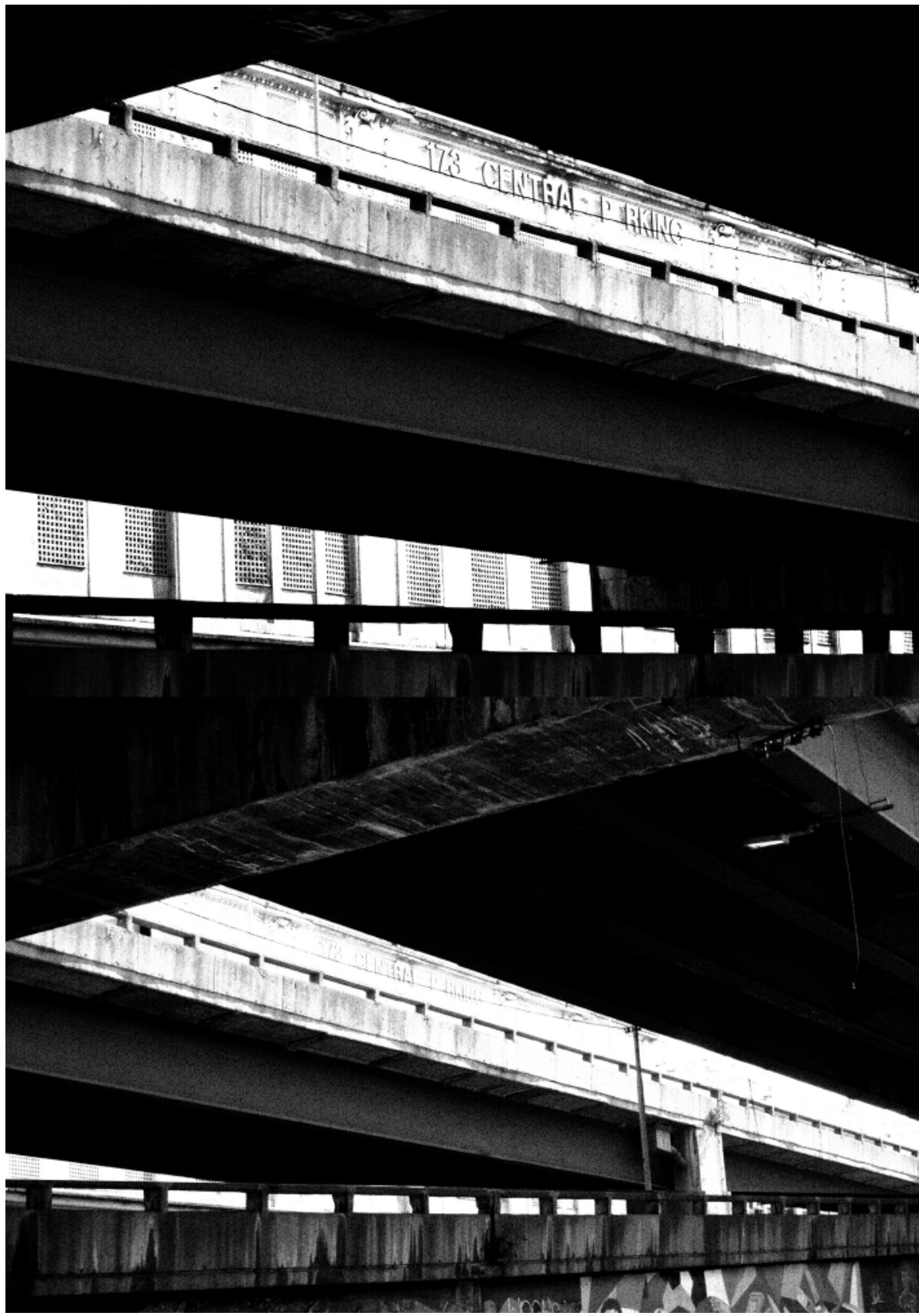

Adeus Perimetral. Documentação autoral sobre a derrubada do elevado da Perimetral. Rio de janeiro10/08/2015

EM PAUTA, Rio de Janeiro - $1^{\circ}$ Semestre de 2015 - n. 35, v. 13, p. 203- 224

Revista da Faculdade de Serviço Social da Universidade do Estado do Rio de Janeiro 


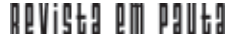

\} FOTOGRAFIA ENTRE CONFRONTO E ARTE - BALTAR, L.

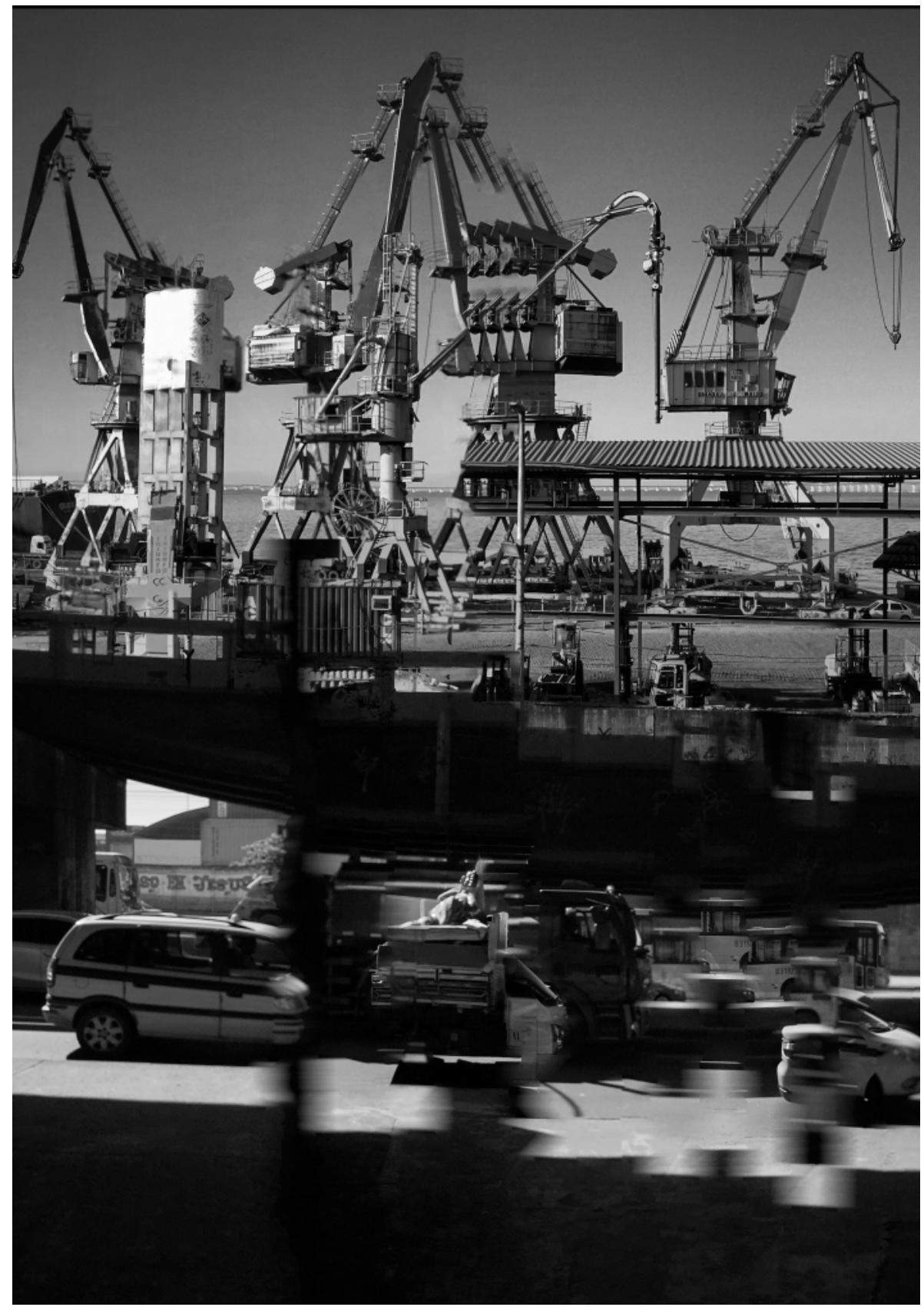

Adeus Perimetral. Documentação autoral sobre a derrubada do elevado da Perimetral.

Rio de janeiro10/08/2015

EM PAUTA, Rio de Janeiro - 1 $^{\circ}$ Semestre de 2015 - n. 35, v. 13, p. 203- 224 


\section{ReVigta dil paltg}

\} FOTOGRAFIA ENTRE CONFRONTO E ARTE - BALTAR, L. \}

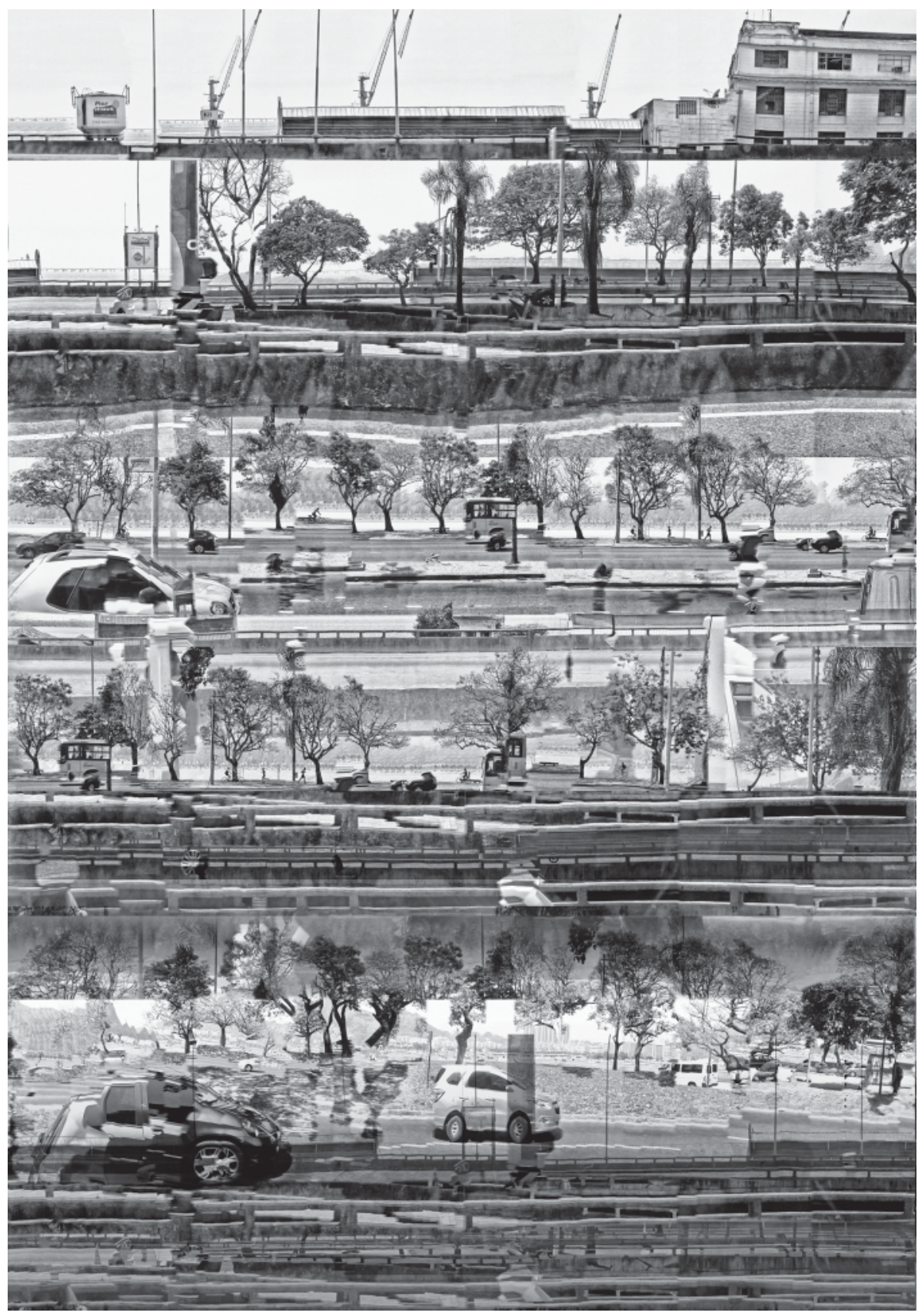

Ensaio Espelhos e Janelas. Documentação autoral sobre os deslocamentos através da cidade usando transporte coletivo. Rio de janeiro 10/08/2015

EM PAUTA, Rio de Janeiro - $1^{\circ}$ Semestre de 2015 - n. 35, v. 13, p. 203- 224 


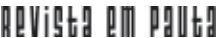

\} FOTOGRAFIA ENTRE CONFRONTO E ARTE - BALTAR, L.

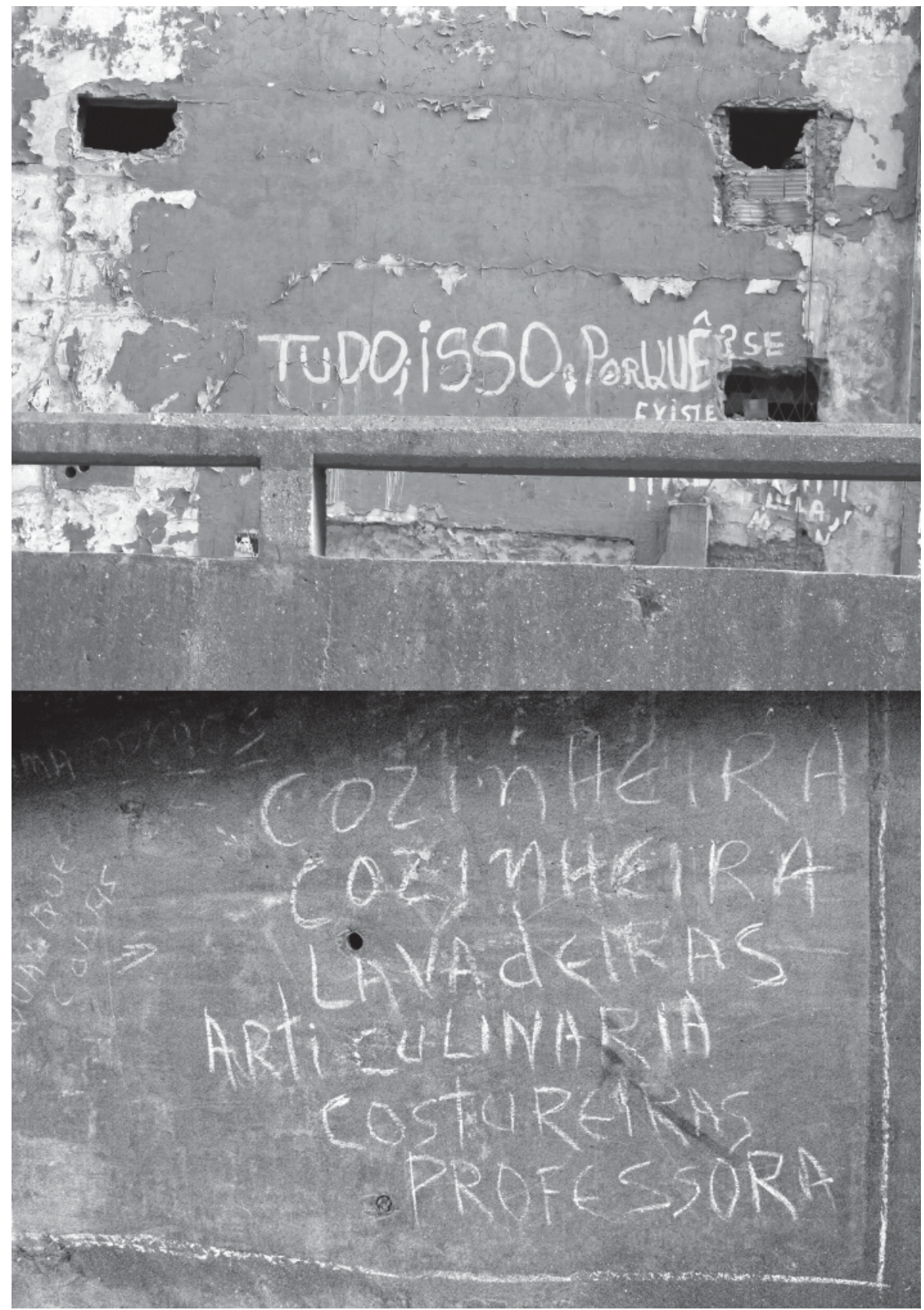

Adeus Perimetral. Documentação autoral sobre a derrubada do elevado da Perimetral. Rio de janeiro10/08/2015

EM PAUTA, Rio de Janeiro - $1^{\circ}$ Semestre de 2015 - n. 35, v. 13, p. 203- 224 